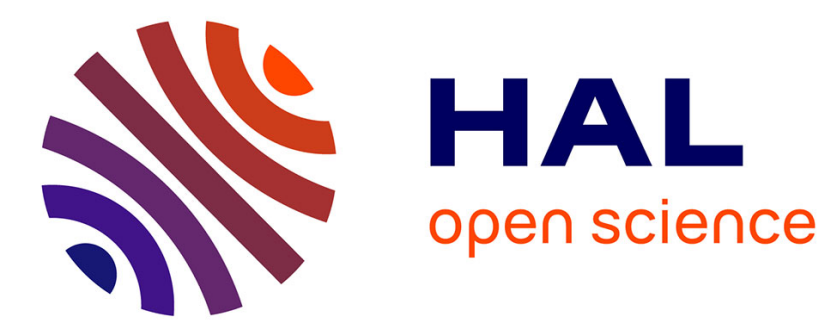

\title{
Ligands and DNA in the allosteric control of retinoid receptors function
}

\author{
Pierre Germain, Natacha Rochel, William Bourguet
}

\section{To cite this version:}

Pierre Germain, Natacha Rochel, William Bourguet. Ligands and DNA in the allosteric control of retinoid receptors function. Essays in Biochemistry, 2021, 10.1042/EBC20200168 . hal-03424056

\section{HAL Id: hal-03424056 \\ https://hal.science/hal-03424056}

Submitted on 16 Nov 2021

HAL is a multi-disciplinary open access archive for the deposit and dissemination of scientific research documents, whether they are published or not. The documents may come from teaching and research institutions in France or abroad, or from public or private research centers.
L'archive ouverte pluridisciplinaire HAL, est destinée au dépôt et à la diffusion de documents scientifiques de niveau recherche, publiés ou non, émanant des établissements d'enseignement et de recherche français ou étrangers, des laboratoires publics ou privés. 


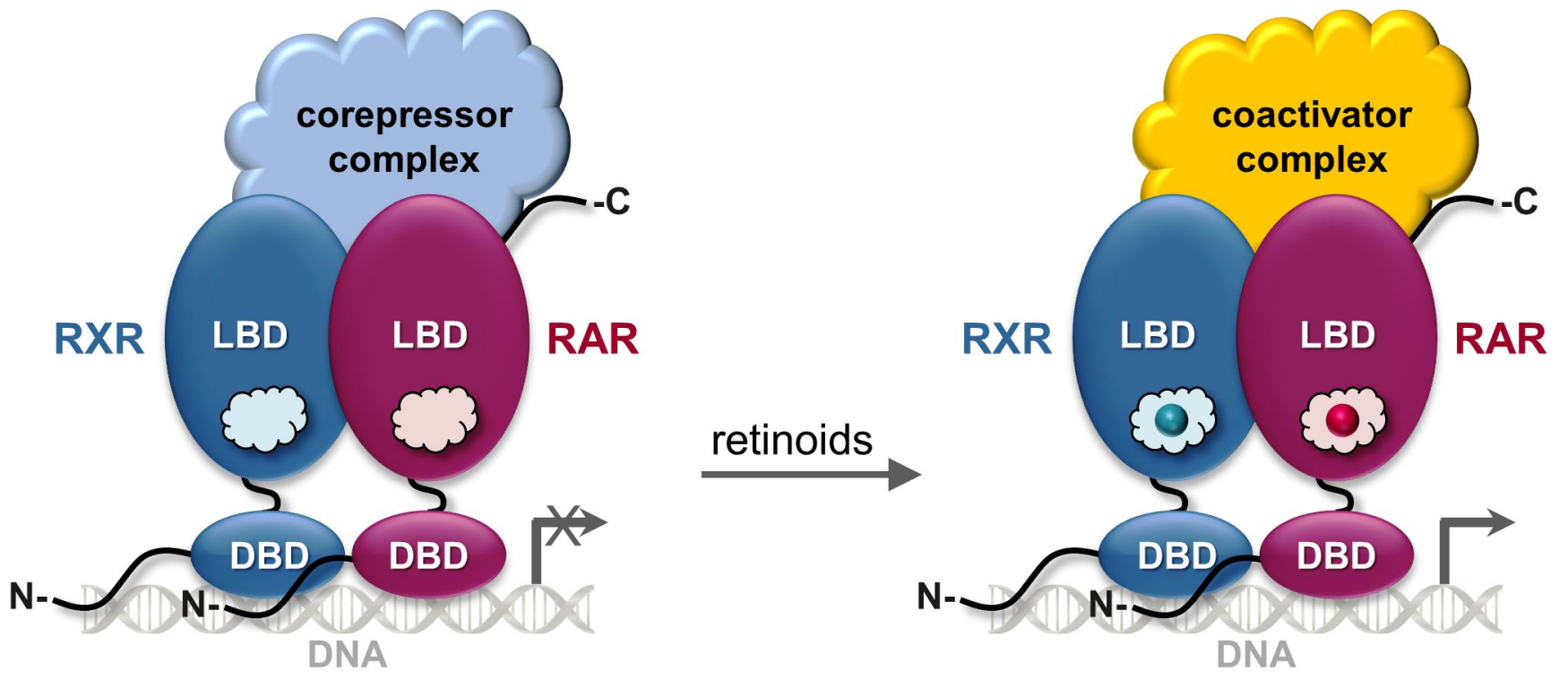


a

\section{RARES}

DR5 RARb2 GGTTCAccgaaAGTTCA

DR2 Hoxa10 AGTTCAgaAGGTCA

DR1 Ramp2 AGTTCAaGGGTCA

DR0 Hoxb13 AGGTCAAGGCCA

IR0 Trim16 GGGTCATGACCC

DR8 Mafa AGGTCAgaAgTTCAAGGTCA

Dedd AGGTCÀcgatctggAGTTCA b
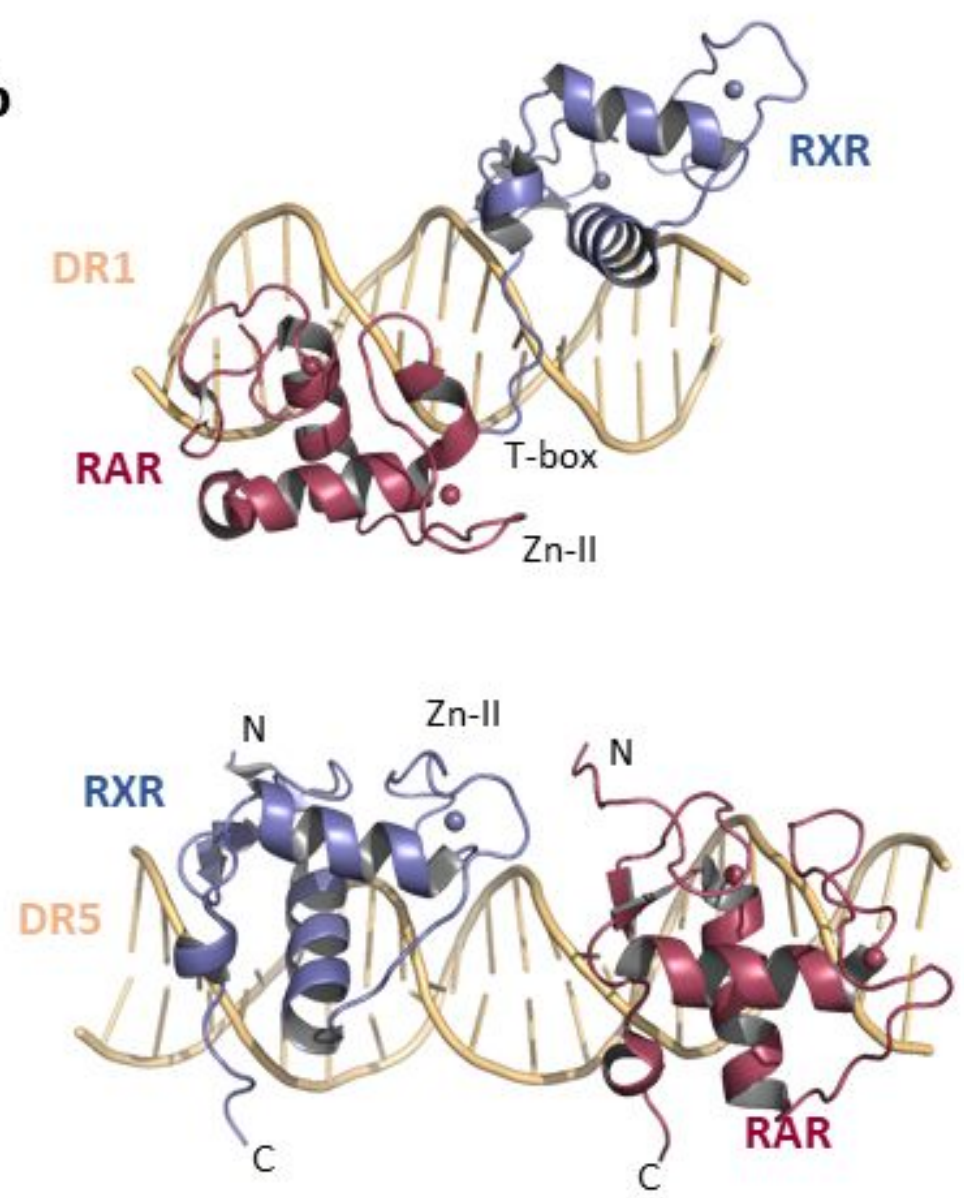


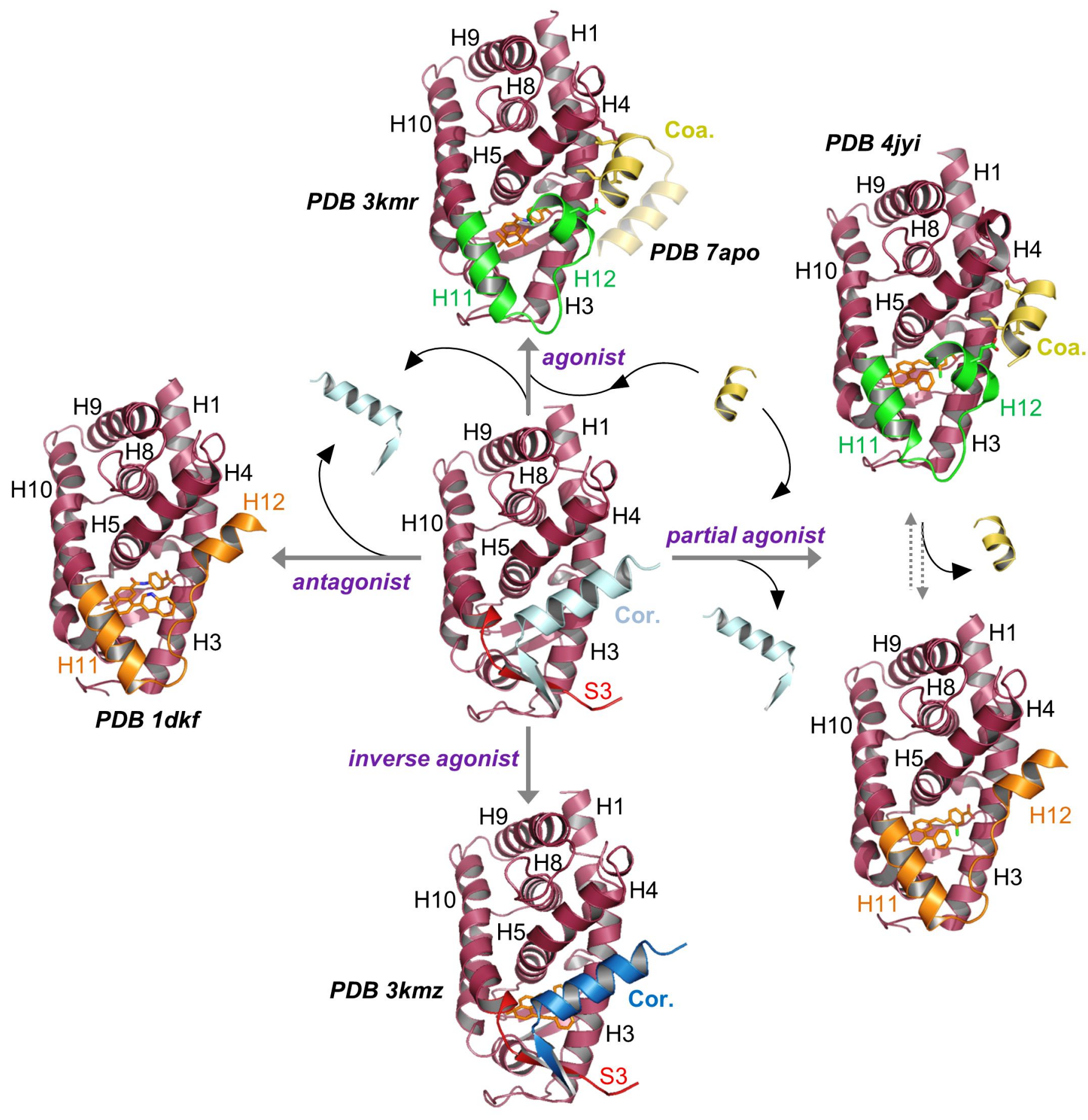




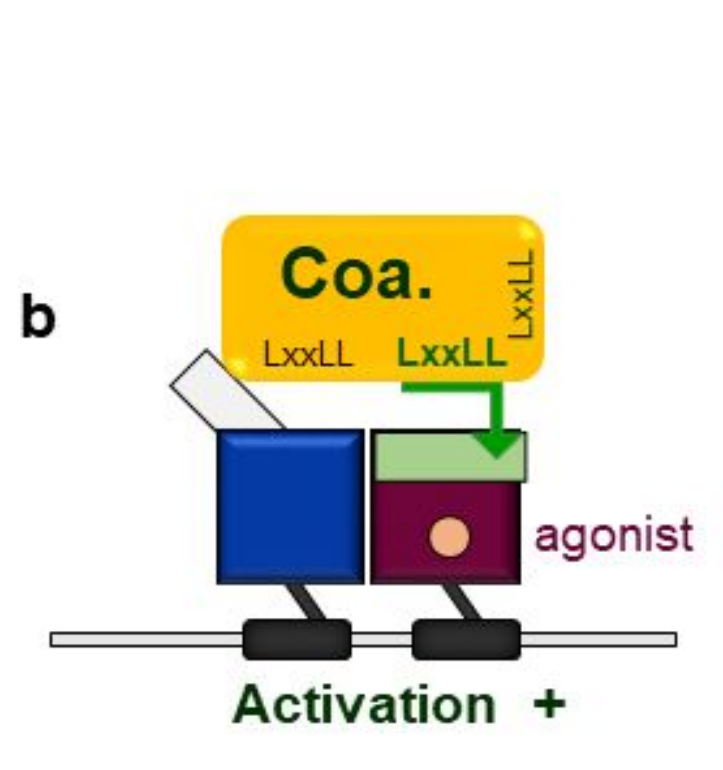

$\sqrt{ }+$ RXR agonist

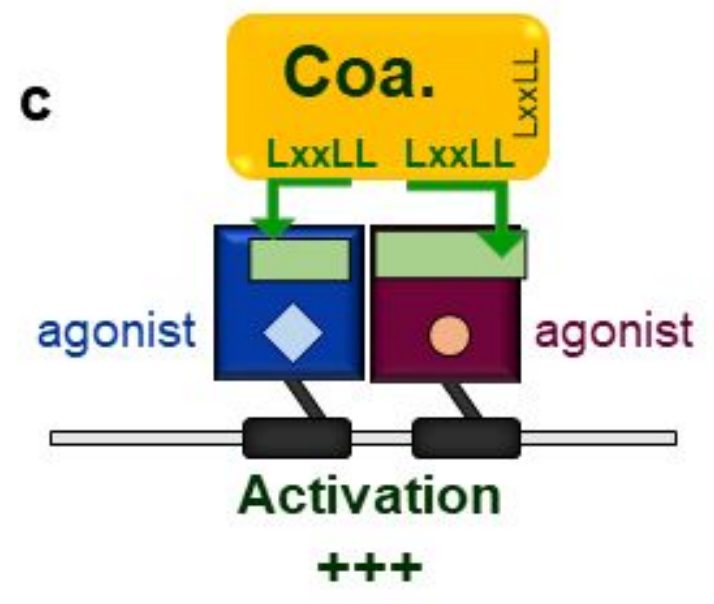

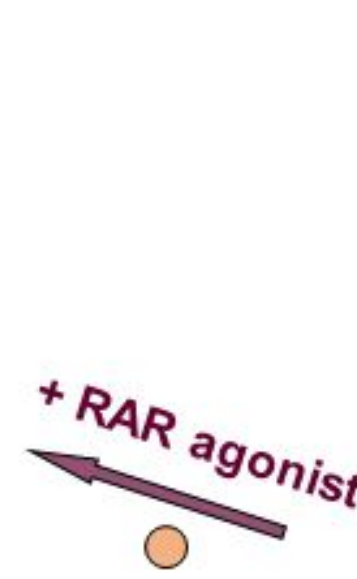

a
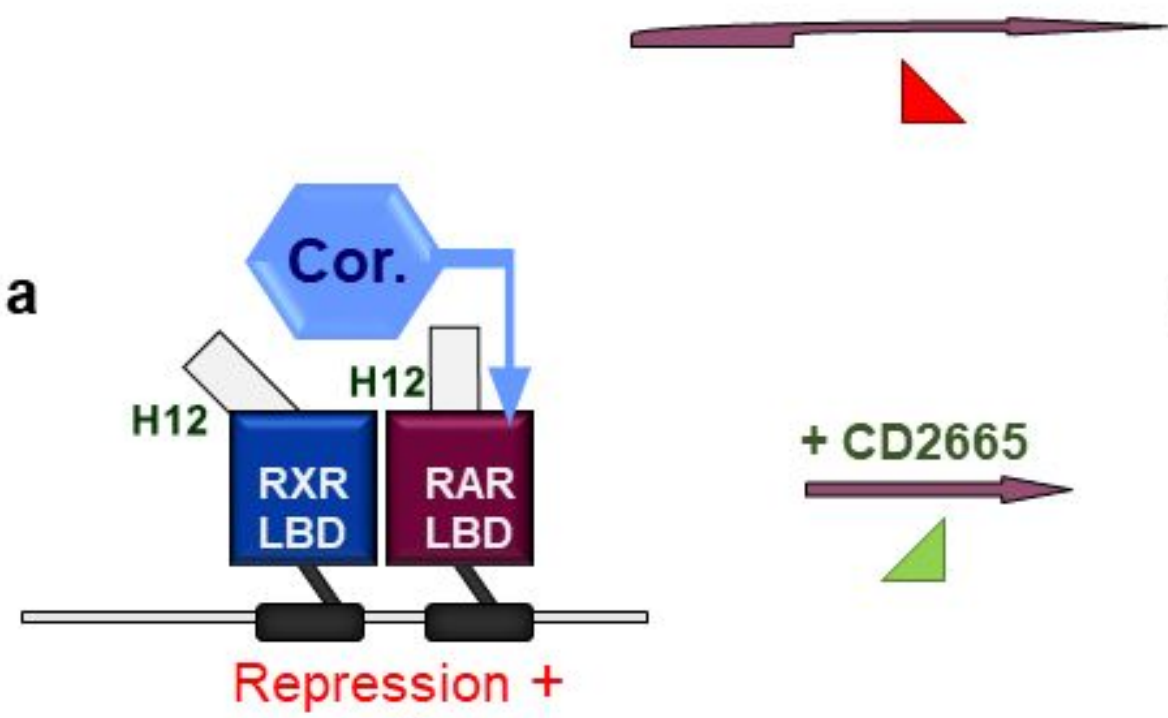

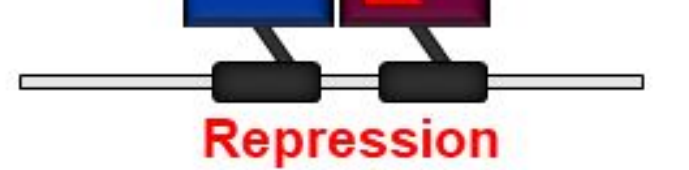

$$
+++
$$

e
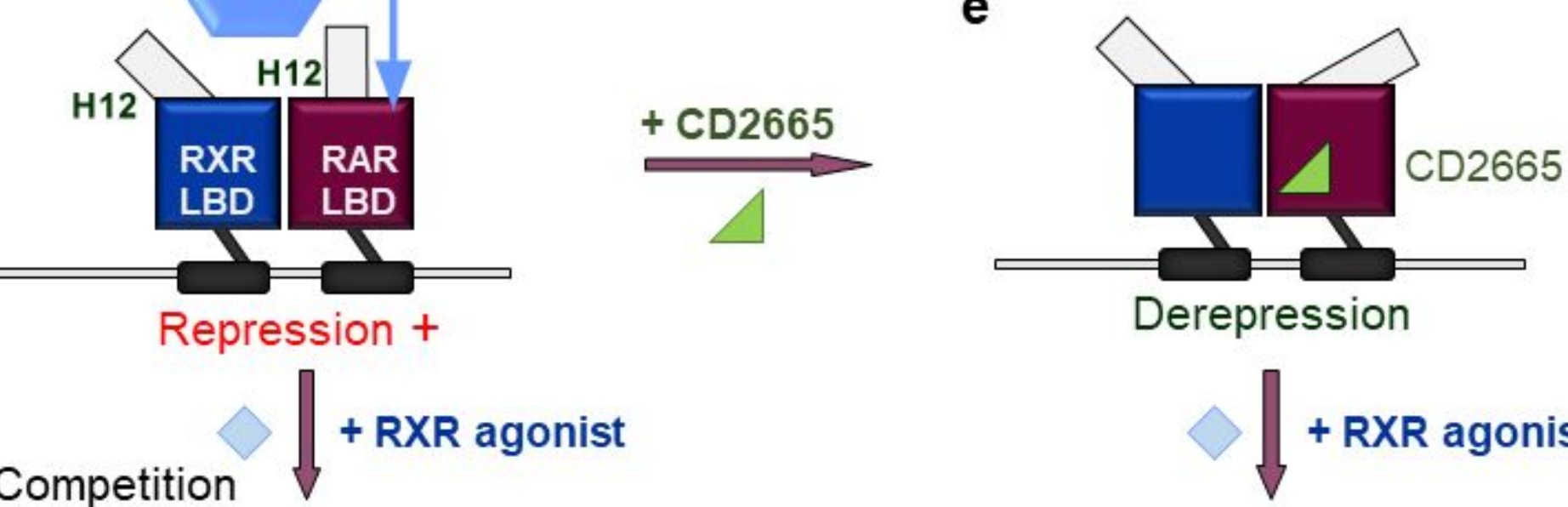

d

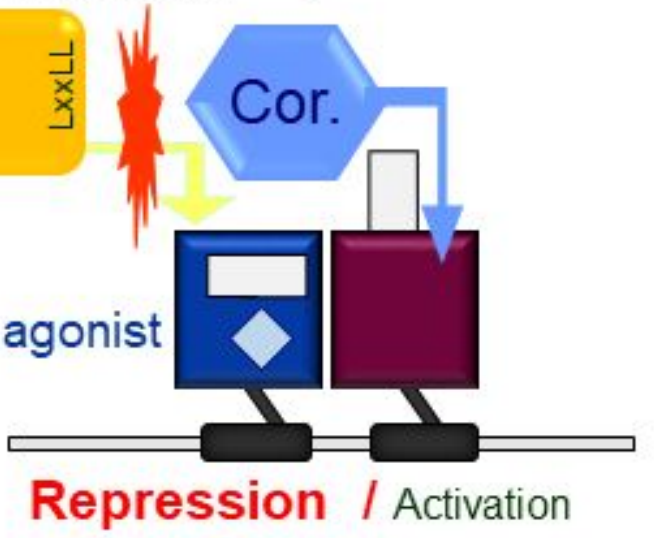

\section{Coa.}

f

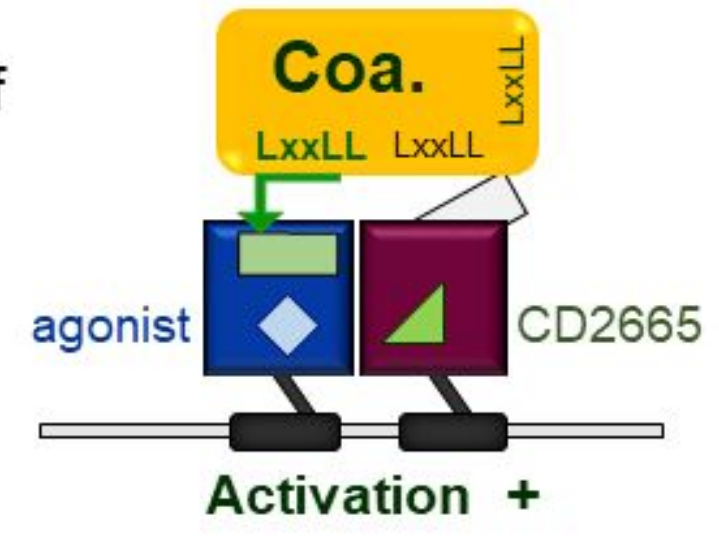




\title{
Ligands and DNA in the allosteric control of retinoid receptors function
}

\author{
Pierre Germain $^{1}$, Natacha Rochel ${ }^{2}$, William Bourguet ${ }^{1^{*}}$ \\ ${ }^{1}$ Centre de Biologie Structurale (CBS), Inserm, CNRS, Univ Montpellier, Montpellier, France \\ ${ }^{2}$ Institut de Génétique et de Biologie Moléculaire et Cellulaire (IGBMC), Inserm, CNRS, Univ \\ Strasbourg, Illkirch, France
}

*Corresponding author: bourguet@ cbs.cnrs.fr

\section{Summary points}

Retinoid receptors control a wide variety of physiological processes and as such represent important drug targets to combat and prevent several cancers, skin and blood diseases or metabolic disorders.

Structural and functional analyses have provided deep insight into the molecular mechanism of their regulation via ligand- and DNA-induced allosteric conformational changes which are the basis of their communication with the cellular environment.

The complexity of incoming signals and their integration is still not fully understood and additional studies associating integrative structural biology, genomics and single-cell analysis at various time and size scales are needed to better apprehend retinoid functions. 


\begin{abstract}
Retinoids are a family of compounds that include both vitamin A (all-trans retinol) and its naturally occurring metabolites such as retinoic acids (e.g. all-trans retinoic acid) as well as synthetic analogs. They are critically involved in the regulation of a wide variety of essential biological processes, such as embryogenesis and organogenesis, apoptosis, reproduction, vision, and the growth and differentiation of normal and neoplastic cells in vertebrates. The ability of these small molecules to control the expression of several hundred genes through binding to nuclear ligand-dependent transcription factors accounts for most of their functions. Three retinoic acid receptor (RAR $\alpha, \beta, \gamma)$ and three retinoid $\mathrm{X}$ receptor $(\mathrm{RXR} \alpha, \beta, \gamma)$ subtypes form a variety of RXR-RAR heterodimers that have been shown to mediate the pleiotropic effects of retinoids through the recruitment of high-molecular weight coregulatory complexes to response element DNA sequences found in the promoter region of their target genes. Hence, heterodimeric retinoid receptors are multi-domain entities that respond to various incoming signals, such as ligand and DNA binding, by allosteric structural alterations which are the basis of further signal propagation. Here, we provide an overview of the current state of knowledge with regards to the structural mechanisms by which retinoids and DNA response elements act as allosteric effectors that may combine to finely tune RXR-RAR heterodimers activity.
\end{abstract}




\section{Introduction}

The three retinoic acid receptor subtypes $\alpha, \beta$ and $\gamma$ (RAR $\alpha, \beta, \gamma$; NR1B1-3 according to the official nomenclature) transduce retinoid signaling, in embryo and adult life, through heterodimeric complexes with the three retinoid $\mathrm{X}$ receptor paralogs $\alpha, \beta$ and $\gamma(\mathrm{RXR} \alpha, \beta, \gamma$; NR2B1-3) as partners $[1,2]$. By controlling gene transcription, the retinoid receptors play multiple roles in vertebrate development, organogenesis, homeostasis, immune functions, and reproduction [3-5] and represent important drug targets [6-8]. Their activation function is finely tuned by small and mostly hydrophobic ligands (see Table 1 for examples of natural and synthetic retinoids), multiple transcriptional co-regulators (corepressors and coactivators) and post-translational modifications (PTMs), resulting from crosstalk between different signaling routes $[9,10]$. Similar to other nuclear receptors (NRs), they display a modular organization with two conserved domains, namely the ligand-binding domain (LBD, moderately conserved) and the DNA-binding domain (DBD, highly conserved), that contain the ligand-dependent activation function 2 (AF-2), and the recognition motif of their binding sites on

DNA response elements, respectively (Fig. 1).
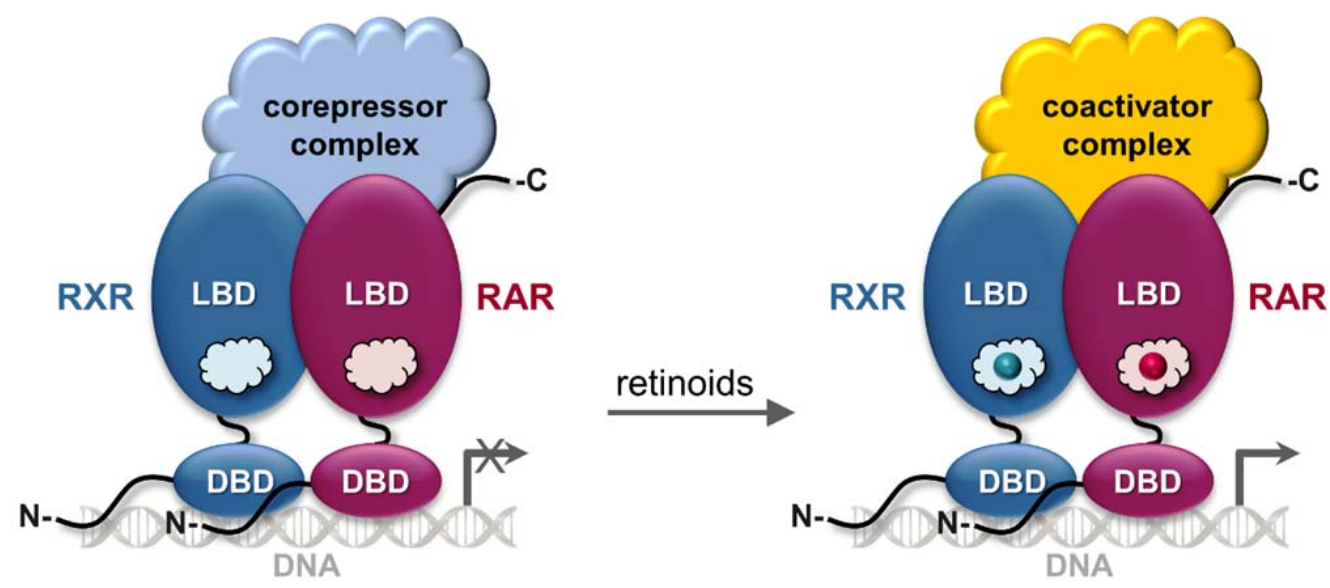

Figure 1: The RXR-RAR heterodimers act as repressors and activators of gene transcription. RXRRAR heterodimers bind via their DNA-binding domains (DBD) to specific retinoic acid response element DNA sequences found in the promoter region of retinoid target genes. In the absence of ligand, the RXR-RAR heterodimer recruits the corepressor proteins NCoR or SMRT and associated enzymatic factors inducing an inactive condensed chromatin structure, preventing transcription. Upon retinoid binding to the RAR ligand-binding domain (LBD), corepressors are released, and coactivators of the SRC family are recruited. The subsequent recruitment of epigenetically active and/or chromatinmodifying complexes such as histone acetyltransferases or histone arginine methyltransferases leads to chromatin alterations that facilitate activation of target gene expression by the basal transcriptional machinery. RXR ligands may act synergistically with RAR ligands to enhance transcription. 
The other functional domains are unstructured and less conserved. These regions are the N-terminal domain containing the ligand independent activation function 1 (AF-1), a short linker sequence allowing the proper orientation of DBDs and LBDs within DNA-bound dimers, and a poorly understood C-terminal region which is present in RARs but not in RXRs [11, 12]. RXR-RAR heterodimers control transcription via several distinct mechanisms, including both repression and activation. In the absence of ligand, the heterodimer recruits the corepressor proteins NCOR1 (formerly NCoR) or NCOR2 (formerly SMRT) serving as docking platforms to tether the repression machinery to RXR-RAR. Retinoid binding induces conformational changes in the heterodimer, allowing corepressor dissociation and the recruitment of members of the NR coactivator 1-3 (NCOA1-3) families of proteins such as SRC1, TIF2 or RAC3 (Fig. 1). Both corepressor and coactivator complexes act by altering the chromatin structure surrounding the promoter of target genes to allow their repression or activation, respectively [13-16].

Structural studies of NRs at the atomic level began in the early 1990s with X-ray crystallography and nuclear magnetic resonance (NMR) analyses providing the first snapshots of DBDs alone or bound to their DNA targets [17]. In the mid-1990s, the crystal structures of the unliganded (apo) RXR $\alpha$ and RAR $\gamma$ bound to all-trans-retinoic acid (ATRA) were the first reported NR LBD structures at atomic resolution. They revealed a new protein fold which was later on demonstrated to be prototypical of all the family members. Comparison of the two structures suggested a molecular mechanism for the ligand-induced activation involving conformational changes upon ligand binding [18]. Later, crystallographic studies using RARs and RXRs in complex with a variety of synthetic ligands ranging from agonists to antagonists through inverse or partial agonists (Table 1) provided extensive insights into the molecular basis of ligand action, revealing how different pharmacological classes of ligands allosterically remodel the receptor surface to enhance or reduce interaction with a given type of coregulator $[11,19]$. Structural studies allowed the precise delineation of the different binding surfaces of LBDs, including interaction sites for co-regulators and partner receptors [19, 20]. Based on these data, a structure-based sequence analysis led to the recognition of two classes within the superfamily with NRs of class I forming homodimers (e.g. steroid hormone receptors) while class II members form stable heterodimers with RXR [21]. More recently, crystallographic, cryo-electron microscopy (cryo- 
EM) and solution studies have allowed the determination of structures of nearly full-length NRs, including that of the RXR-RAR heterodimer, bound to their cognate response elements, revealing their overall topologies and the role of DNA in domain organization and communication $[11,22,23]$. Solution studies using hydrogen/deuterium-exchange coupled mass-spectrometry (HDX-MS), small angle X-ray scattering (SAXS), fluorescence or NMR approaches further highlighted the importance of structural dynamics, transient interactions and intrinsic disorder in the fine tuning of retinoid receptors function [24]. In this chapter, we provide a current comprehensive view as to how retinoidal ligands and DNA response elements allosterically control the precise regulation of RXR-RAR heterodimers.

\section{Basic principles of DNA recognition by RXR-RAR heterodimers}

RXR-RAR heterodimers bind to specific DNA sequences, called retinoic acid response elements (RAREs), that are typically composed of two direct repeats (DR) of a core hexameric motif, $(\mathrm{A} / \mathrm{G}) \mathrm{G}(\mathrm{G} / \mathrm{T}) \mathrm{TCA}$ and are located in the regulatory sequences of target genes. The number of spacer nucleotides between the half-sites was initially defined for various RXR heterodimers in a simplified manner by the '1-5 rule': RXR-RXR and RAR-RXR (DR1), RXR-RAR (DR2), RXR-VDR (DR3), RXR-TR (DR4) and RXR-RAR (DR5) [25]. Genome-wide chromatin immunoprecipitation followed by sequencing data allowed the characterization of RAR cistromes in various cell types [26-32] revealing that in addition to sites comprising the consensus direct repeat DR1, DR2 or DR5 elements, numerous sites comprising non-canonical sequences were detected (Fig. 2a), including DR1, 2 and 5 with non-canonical half-site sequences, inverted repeat 0 (IR0) elements and novel spacing topology elements, the DR0 and DR8 elements [30]. Biochemical and biophysical studies have revealed that RXR-RAR binds with comparable affinities in the nanomolar range to the various RAREs [30, 33]. DNA sequences and topology have been shown to act as allosteric effectors to modulate RAR activity, acting on the recruitment of coactivator or corepressor proteins. Positive or negative regulations have been shown to be strongly influenced by the spacing of the DNA elements to which they bind [34].

Current knowledge of the structural basis of specific DNA recognition by RXR-RAR heterodimer at atomic level is limited to complexes bound to DR1 or DR5 elements, comprising the crystal structures 
of the RXR $\alpha$-RAR $\alpha$ DBDs [35] and RXR $\beta$-RAR $\alpha$ deleted of RAR and RXR N-terminal disordered regions [36] bound to an idealized or consensus DR1 sequence with identical half-sites and the crystal structure of RXR $\alpha$-RAR $\alpha$ DBDs bound to RAR $\beta 2$ DR5, the only one with natural RARE [34]. The DBD core is highly conserved among NR family. It is composed of approximately 66 amino acid residues which form a tertiary structure composed of an N-terminal $\beta$-hairpin and two $\alpha$-helices followed by a short C-terminal helix and an extension (Fig. 2b). The N-terminal $\alpha$-helix fits into the major groove of the DNA and makes direct and water mediated hydrogen bonds with the nucleotide sequence. The $\mathrm{C}$-terminal $\alpha$-helix is perpendicular to the $\mathrm{N}$-terminal helix and stabilizes the core of the DBD.

On both DR1 and DR5 elements, RAR and RXR bind asymmetrically in a head to tail manner but with reversed polarity (Fig. 2b). The spacing between the two motifs controls the position of the two bound receptors since each base pair leads to a rotation of about $35^{\circ}$ and $3.4 \AA$ length increase, thus leading to different dimerization surface in the two complexes. Interestingly, binding of the heterodimer to the DR1 and DR5 induce a DNA curvature not observed in the corresponding RXR homodimer complex on the same DNA element ([35] and unpublished data), to foster heterodimer interactions and resulting in higher affinity of the heterodimer over homodimer. In DR1 complex, the interface is formed by the C-terminal T-box of RXR DBD with the Zn-II region of RAR DBD [35, 36]. While in DR5 complex, the dimerization interface involves residues from the second $\mathrm{Zn}$ module of the RXR DBD and the N-terminal region of RAR [34]. In addition to spacing and topology of the response elements, the nature of the half-site sequences in contact with the DBD also modulates DBD geometry and the interactions between the two DBDs, as shown for GR [37] and RXR homodimers [38]. In the RXR-RAR heterodimer DNA complexes [34-36], each DBD forms sequence-specific direct and water mediated base contacts that involve highly conserved residues: Glu153, Lys156 and Arg161 for RXR, and Glu106 and Lys109 for RAR, as well as sequence-specific additional interactions. Different DNA sequences of the RAREs as observed in the genome will exert an allosteric regulation of the DBD heterodimer through changes in contacts at the dimerization interface. This allosteric regulation of DBD positioning may propagate to other domains of the receptor and hence contribute to the fine-tuning of transcription (as discussed further below). 
a

\section{RARES}

$\begin{array}{lll}\text { DR5 } & \text { RARb2 } & \text { GGTTCAccgaaAGTTCA } \\ \text { DR2 } & \text { Hoxa10 } & \text { AGTTCAgaAGGTCA } \\ \text { DR1 } & \text { Ramp2 } & \text { AGTTCAaGGGTCA } \\ \text { DR0 } & \text { Hoxb13 } & \text { AGGTCAAGGCCA } \\ \text { IR0 } & \text { Trim16 } & \text { GGGTCATGACCC } \\ \text { DR8 } & \text { Mafa } & \text { AGGTCÄaAGTTCAAGGTCA } \\ & \text { Dedd } & \text { AGGTCÄcgatctggAGTTCA }\end{array}$
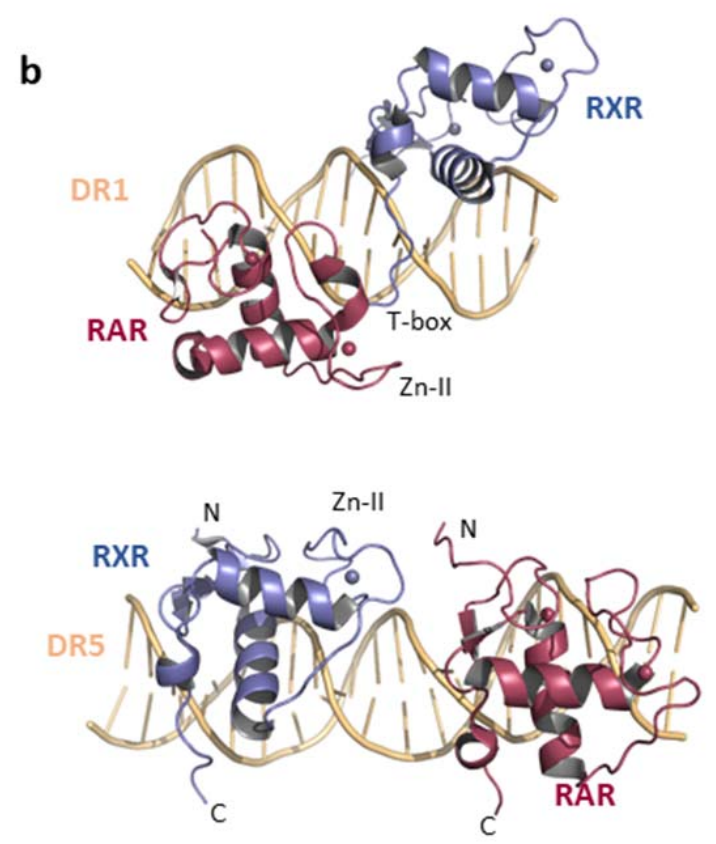

Figure 2: DNA binding of RXR-RAR heterodimers to DNA. (a) RAREs are composed of direct repeats (DR) of the hexanucleotide sequence $\left(5^{\prime}-(\mathrm{A} / \mathrm{G}) \mathrm{G}(\mathrm{G} / \mathrm{T}) \mathrm{TCA}-3^{\prime}\right)$ separated by separated by 0 (DR0), 1 (DR1), 2 (DR2), 5 (DR5) or 8 (DR8) nucleotides and inverted repeats separated by 0 (IR0). RAR-RXR binds to these elements with a specific polarity. (b) Crystal structure of the heterodimer formed by RAR (in purple) and RXR (in blue) DNA-binding domains in complex with idealized DR1 (PDB ID: 1DSZ) and RARß2 DR5 (PDB ID: 6XWG).

\section{Structural basis of ligand-regulated co-regulators interaction and exchange}

Crystallographic studies of RAR and RXR LBDs in complex with various corepressor and coactivator fragments have provided deep insights into the structural basis of the interactions between these receptors and transcriptional co-regulators, and their modulation by ligands [19]. The LBD of both RARs and RXRs is organized as an antiparallel $\alpha$-helical sandwich with 12 conserved helices arranged in three layers with a $\beta$-turn (S1 and S2) located between helices H5 and H6. Helices H4, H5, H8, H9 and $\mathrm{H} 11$ are sandwiched between $\mathrm{H} 1, \mathrm{H} 2$ and $\mathrm{H} 3$ on one side and $\mathrm{H} 6, \mathrm{H} 7$ and $\mathrm{H} 10$ on the other side (Fig. 3). In contrast, the C-terminal helix H12 (also termed activation or AF-2 helix) is flexible and can adopt various conformations depending on the type of bound ligand. This LBD architecture generates a ligand-binding pocket (LBP) primarily made of hydrophobic residues from helices H3, $\mathrm{H} 5, \mathrm{H} 7, \mathrm{H} 11$ and the $\beta$-sheet segment. Structural studies have revealed that ligands are stabilized in the LBPs through extensive van der Waals contacts and a network of ionic and hydrogen bonds between their carboxylate moieties, a conserved arginine in H5, and water molecules. 
In the absence of ligand or in the presence of so-called inverse agonists, RAR exhibits strong repressive activity that is brought about by the recruitment of corepressors. A combination of structural and functional studies revealed that RARs specifically interact with a bipartite and short structural motif found in the NR interaction domain (NRID) of corepressors [39]. This motif comprises a four-turn helix with the conserved $\operatorname{Lxxx} \operatorname{Ixx}(\mathrm{I} / \mathrm{V}) \operatorname{Ixxx}(\mathrm{Y} / \mathrm{F})$ sequence that docks to a hydrophobic surface of the LBD that is formed by residues from helices $\mathrm{H} 3$ and $\mathrm{H} 4$, and an N-terminal extended $\beta$-strand forming an antiparallel $\beta$-sheet with the RAR residues residing after helix H10 (Fig. 3, center panel). Binding of inverse agonist (e.g. BMS493) stabilizes this specific interface and therefore enhances transcriptional silencing (Fig. 3, lower panel). In contrast, binding of any other kind of ligands to RARs induces a $\beta$-strand to $\alpha$-helix transition that allows helix H11 formation which in turn provokes corepressor release. In the case of agonists (e.g. AM580, Fig. 3, upper panel) and to a lesser extent partial agonists (e.g. BMS641, Fig. 3, right panel), this secondary-structure switch is followed by the rearrangement of the C-terminus of RAR LBD into helix H12 that is stabilized in the so-called active position $[39,40]$. This particular location of the activation helix defines a hydrophobic surface comprising the C-terminal part of helix H3, helix H4 and H12, and specifically recognized by short LxxLL motifs, reminiscent of the longer $\operatorname{Lxxx} \operatorname{Ixx}(\mathrm{I} / \mathrm{V}) \operatorname{Ixxx}(\mathrm{Y} / \mathrm{F})$ sequence of corepressors. The short coactivator helix is held in place by interactions of the leucine residues with the hydrophobic groove and by hydrogen bonds with a lysine at the C-terminus of $\mathrm{H} 3$ and a glutamate in $\mathrm{H} 12$ which together form a "charge clamp". A more recent structure with a longer coactivator-derived peptide revealed how LxxLL flanking regions may drive specificity in coactivator recognition (Fig. 3, upper panel). More specifically, the structure shows that the C-terminal extension of the LxxLL motif folds as a long $\alpha$-helix making hydrophobic contacts with residues from both the LxxLL helix and RAR helices $\mathrm{H} 3$ and $\mathrm{H} 12$, thereby inducing a three-fold increase of the affinity of the LxxLL motif for RAR but not for RXR [41]. In contrast to full agonists, partial agonists incompletely stabilize the active form of the receptor (Fig. 3, right panel). The partial activity of these compounds is a consequence of the lower interaction strength between $\mathrm{H} 12$ in its active position and the $\mathrm{H} 3 / \mathrm{H} 11$ surface that renders this helix more dynamic $[42,43]$. 


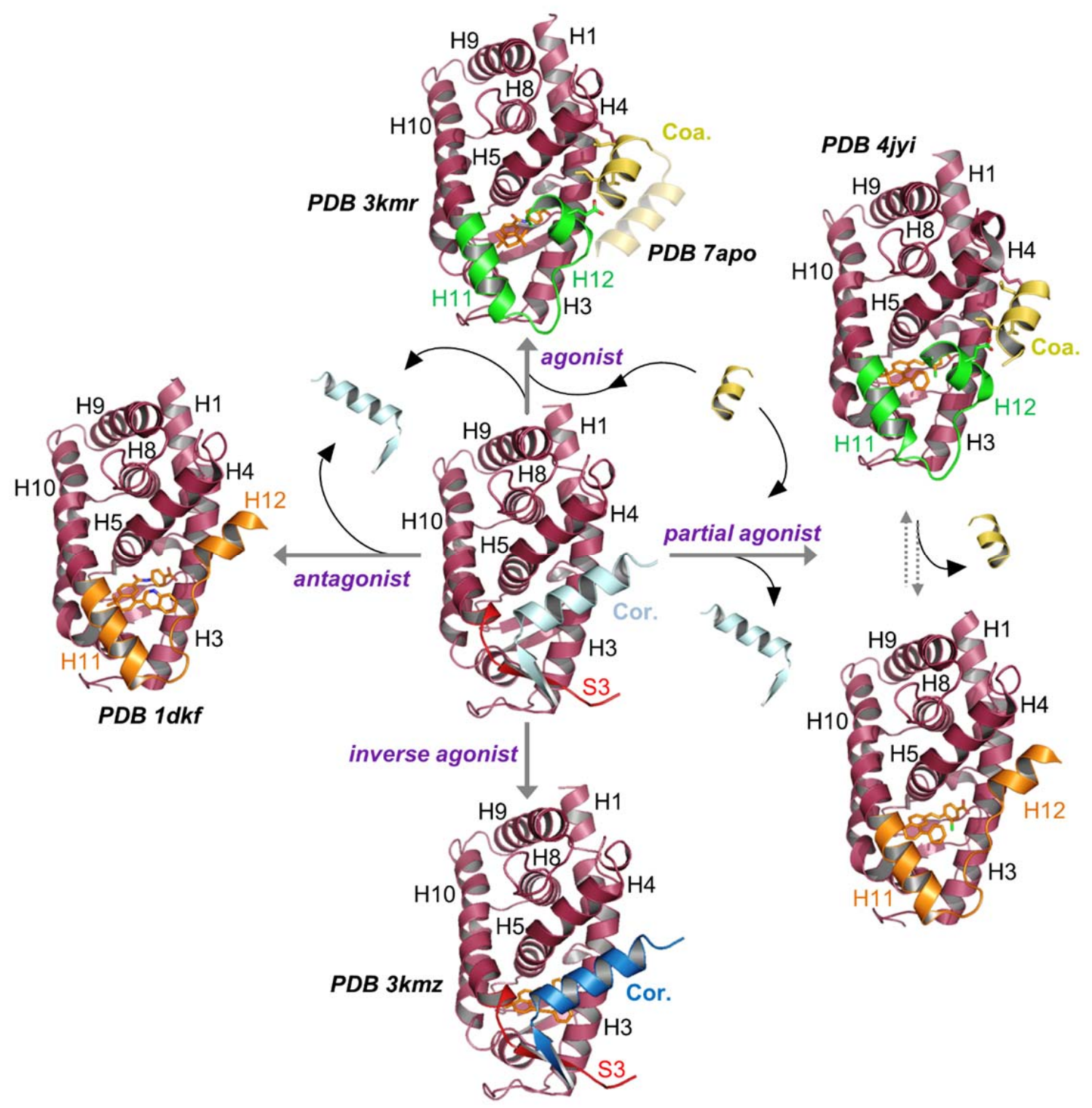

Figure 3: Structural basis of retinoid receptor modulation. Structures of the ligand-binding domain (LBD) of RAR are shown in the absence (center panel) and in the presence of different pharmacological classes of ligands and in complex with various coactivators (Coa.) and corepressor (Cor.) fragments. The core LBD is shown in raspberry color, whereas the color of the varying Cterminal secondary structural elements varies according to the receptor activity state. The corepressor bound conformation (repressive state) is shown in red, the coactivator-bound conformation (active state) is highlighted in green and the antagonist-bound conformation (silent state) is represented in orange. Corepressor and coactivator fragments are shown in blue and yellow, respectively. The dark blue color of the corepressor fragment in the inverse agonist-bound structure denotes higher interaction with RAR LBD relative to the unliganded state (light blue color). Ligands are displayed in their ligand-binding pockets as orange sticks. Important secondary structural elements discussed in the text are labeled (helix: H, strand: S). PDB codes indicate existing structures. PDBs $3 \mathrm{kmr}$ and 7apo denote Am580-bound RAR $\alpha$ LBD in complex with a short LxxLL-containing peptide (yellow), plus its C-terminal flanking region (transparent yellow), respectively. Images of the unliganded corepressor-bound RAR LBD (center panel) and of the partial agonist-bound LBD in the antagonist conformation (lower right panel) correspond to molecular models deduced from additional structural and functional data. 
Note however that the presence of coactivators helps stabilize the active conformation so the transcriptional outcome of partial agonist binding greatly depends on the intracellular concentration of co-regulators. Last, the crystal structure of RAR LBD in complex with the antagonist BMS614 (Fig. 3, left panel) shows that this compound encompasses a bulky extension protruding between helices $\mathrm{H} 3$ and H11 which is too long to be contained within the LBP with the AF-2 helix in the active conformation. Thus, in the presence of such compound, H12 adopts an alternative conformation by docking to the binding groove shared by coactivators and corepressors, between helices H3 and H4. This relocation prevents any interaction with both co-regulator types and renders the receptor transcriptionally silent [44]. Note that structural and functional studies performed on RXRs have revealed similar mechanisms of regulation, with the notable exception that this receptor interacts poorly with corepressors.

\section{Signaling through the heterodimer}

\section{Lessons from structural studies}

In addition to the allosteric effects of RXR and RAR ligands, the DNA response elements not only serve as docking sites for the receptors but act as allosteric modulator of RXR-RAR activity. Structural analyses revealed that the RAREs induce conformational changes in the DBDs [34, 35], that propagate in more distal regions influencing a variety of receptor functions such as dimerization, ligand and coactivator binding $[34,36,45]$. The structures of the multi-domain RXR-RAR complex truncated of their disordered N-terminal domains were determined by X-ray crystallography in complex with an idealized DR1 element [36] or by a combination of solution structural methods for DR1, DR5 and DR0 response elements from regulated genes [34, 45]. In the crystal and solution structures, the hinges remains flexible and only partially ordered, a flexibility necessary to allow the alternative positioning and engagement of the DBDs onto the various RAREs. The crystal structure of RAR-RXR-DR1 complex revealed that the RAR DBD interacts with its LBD, while RXR domains remain flexibly positioned (Fig. 4, left panel) [36]. In the solution structures, the conformations are elongated and the RXR-RAR LBD dimer (Fig. 4, right panel) appears asymmetrically positioned with respect to the DNA response elements [34]. As a consequence of different DNA binding mode on 
DR5 and DR0 elements, differences in overall conformations and dynamics of the complexes were observed [34]. These differences are expected to lead to large differences in co-regulator binding and to control transcriptional output, as supported by HDX-MS analyses of RXR-RAR-DNA complexes $[34,36]$ and as observed for other NR heterodimers $[46,47]$. The communications pathway between the DNA, the ligand and the coactivator interacting surface have been proposed to involve either DBD-LBD interactions or long range communication through the hinges domains (Fig. 4).
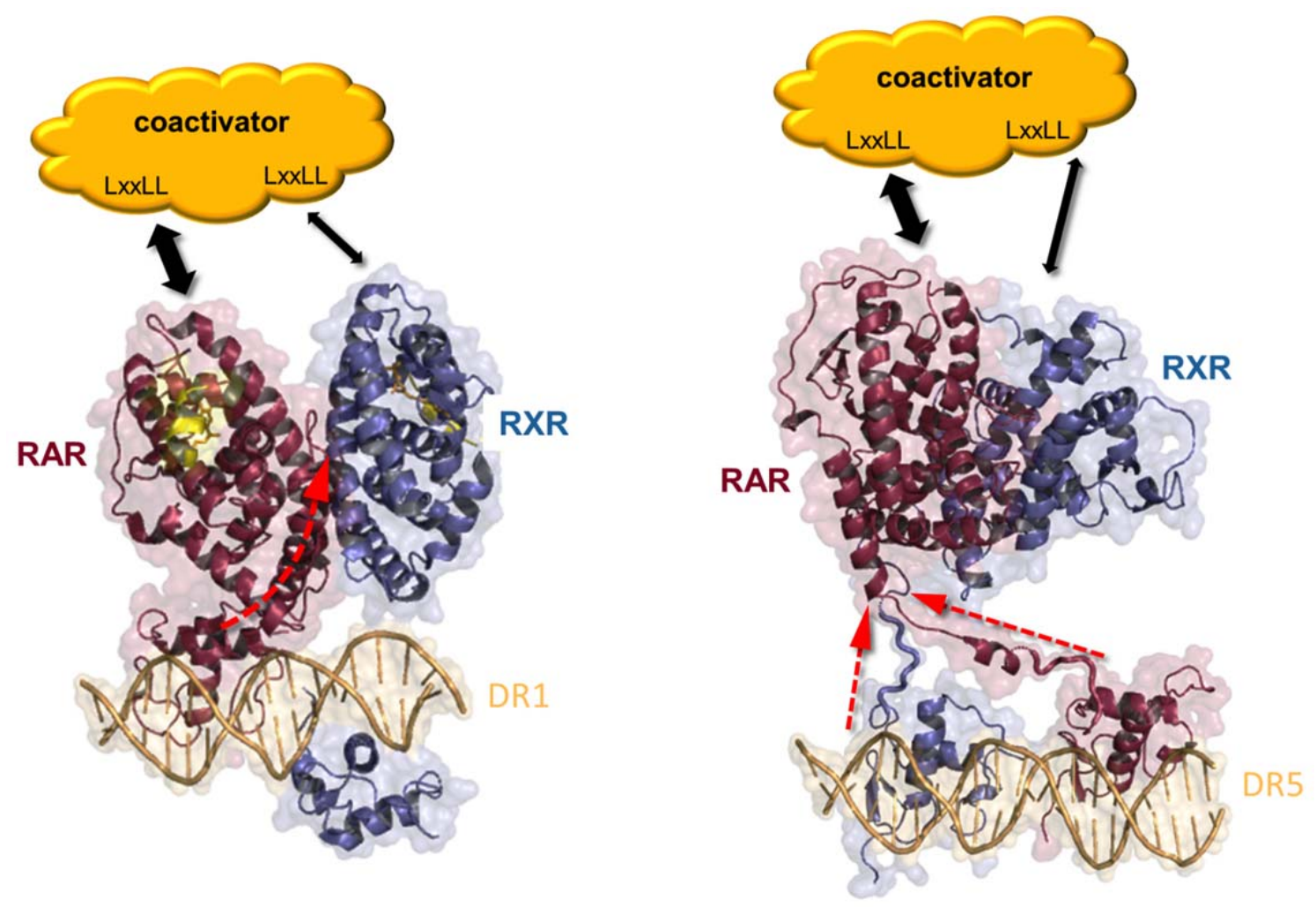

Figure 4: Structures of multi-domain RXR-RAR complexes. Left: Crystal structure of RXR-RAR bound to DR1. Right: Solution structure of RXR-RAR bound to DR5. Modulation of the conformation by DNA binding shown by red arrows leads to ligand-mediated coactivator interactions.

The NRID of corepressors and coactivators are mainly intrinsically disordered regions characterized by the presence of multiple conserved and transiently structured $\operatorname{Lxxx} \operatorname{Ixx}(\mathrm{I} / \mathrm{V}) \operatorname{Ixxx}(\mathrm{Y} / \mathrm{F})$ and $\mathrm{LxxLL}$ motifs, respectively, so that the mechanism by which RAR in the context of the heterodimer with RXR interacts with co-regulators has been a matter of debate. Some studies argued in favor of the deck model where each subunit interacts with one coregulatory binding motif $[36,46,48]$, while other studies reported an asymmetric model where RAR is the unique contributor to the interaction with co- 
regulators [45]. Two recent studies combining of a large set of biophysical and computational methods allowed to somehow reconcile these seemingly conflicting views by demonstrating that NRIDs form highly dynamic complexes with RAR-RXR, with singly and doubly bound species, and that the equilibrium can be modulated by ligands and mutations [41, 49]. Moreover, they revealed that while the NRID of corepressors and coactivators is mainly disordered, it presents transient but robust intramolecular contacts upon interaction with the heterodimer, indicating that disorder-to-order transitions are key events in the regulation of NR heterodimers.

\section{Lessons from functional studies}

The above considerations imply that RXR-RAR heterodimers are the functional entities which regulate expression of target genes raising the question of the relative contributions of each subunit in the transcriptional state of heterodimers. Importantly, both heterodimer subunits retain their own properties in terms of ligand and co-regulator binding [43]. Consequently, an important point is based on the relative affinities of transcriptional co-regulators for RXR and RAR which depend on the ligand binding status of each subunit, making that heterodimer is in equilibrium between repressing and activating states $[39,43,48]$. A recent work indicates that in the absence of ligand for both RXR and RAR, the corepressor may form a transient multisite complex with the heterodimer via two binding motifs and, although RAR represents the main surface for corepressor interaction with the heterodimer, RXR would also play a minor role in its recruitment [49]. In contrast to RAR agonists that can activate heterodimers by inducing corepressor dissociation and coactivator interaction (Fig. 5a, b), RXR-selective agonists are unable to trigger RXR-RAR transcriptional response on their own $[50,51]$. This phenomenon is referred to as RXR "subordination" or "silencing". Though the molecular mechanism responsible for this subordination has been highly debated, it can be best explained by the fact that binding of rexinoid agonists to RXR cannot induce corepressor dissociation from heterodimers and thus permits the recruitment of coactivators because of the inaccessibility of the mutually exclusive binding site of the two co-regulator types (Fig. 5d). But when agonists for each subunit are used in combination, RXR ligands enhance the transcriptional activity of the heterodimer in a synergistic manner (Fig. 5c). Previous and recent works suggested that synergy likely originates 
from the cooperative binding of two LxxLL motifs from one coactivator molecule to RXR-RAR heterodimer $[41,51]$. Accordingly the activating capacity of rexinoids relies only on their ability to induce the recruitment of coactivators and the only way by which rexinoids can significantly contribute to heterodimer activity is in combination with an appropriate RAR ligand. Hence, by releasing corepressor from RAR $\alpha$, the RAR antagonist CD2665 permits agonist-bound RXR to induce the recruitment of coactivators to the RXR-RAR $\alpha$ heterodimer which translates into transcription activation (Fig. 5e, f) [43]. In contrast, binding of an inverse agonist to RAR does prevent the coactivator association onto agonist-bound RXR (Fig. 5g) [39, 43, 51, 52]. The degree of corepressor interaction is therefore a crucial determinant on which pharmacological molecules can act for modulating heterodimer activity.

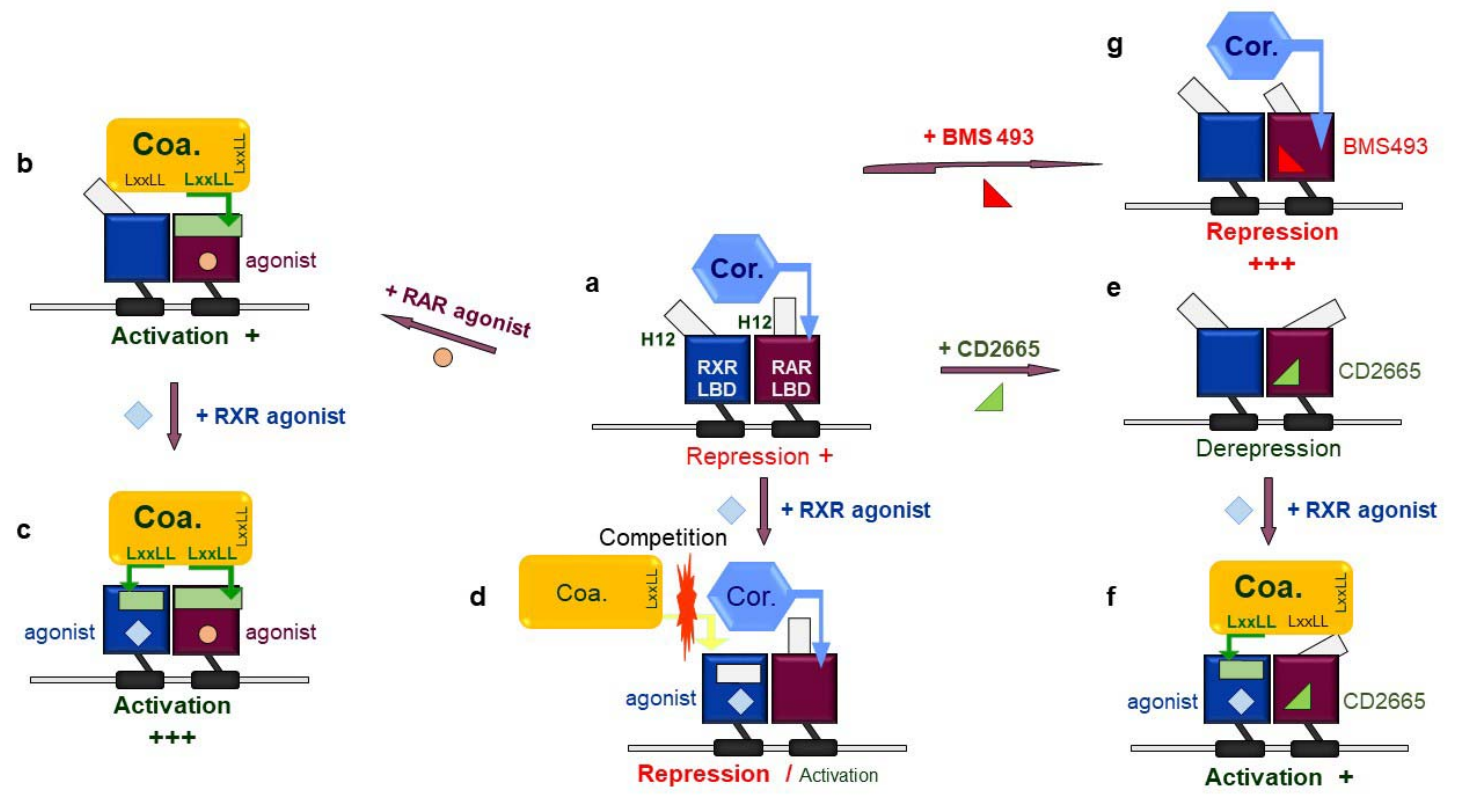

Figure 5: Model for RXR-RAR heterodimer function in the presence of various ligands. The cartoon depicts RXR-RAR bound to a DNA response element and interactions of both corepressor and coactivator as a function of the ligands bound to RAR or RXR or both. (a) In the absence of ligands RXR-RAR heterodimer is associated with a corepressor (Cor.) mainly bound to the RAR subunit. (b) Binding of an RAR agonist provokes a conformational change of RAR LBD such that the corepressor binding interface is disrupted and a novel surface is induced to which the coactivator (Coa.) can bind through a LxxLL motif. As a result RAR agonists dissociate corepressors and recruit coactivators, resulting in transactivation. (c) Further addition of an RXR-selective agonist creates a coactivator binding surface at the RXR LBD allowing a cooperative binding of two LxxLL motifs of one coactivator molecule. (d) In the absence of any RAR ligand an RXR agonist generates a potential coactivator binding interface at RXR LBD but does not enable the dissociation of the corepressor from the RAR subunit. Because of steric interference coactivator is unable to bind to the heterodimer, thus accounting for the so-called RXR subordination. (e) RAR antagonists such as CD2665 destabilize the corepressor interface without generating the surface for coactivator binding. As a result CD2665 is 
transcriptionally inactive by its own. (f) By releasing corepressor from RAR CD2665 allows the recruitment of coactivator by the RXR subunit, resulting in transcriptional synergy. (g) Inverse agonists such as BMS493 can reinforce the interaction between the heterodimer and the corepressor that does enhance silencing.

\section{Perspectives}

Structurally, RXR-RAR heterodimers interact with coactivators or corepressors that are themselves part of large protein complexes, with enzymatic activities affecting the chromatin structure and the transcriptional output. Current structural studies on RXR-RAR coregulatory complexes are limited to domain of coactivator bound to the heterodimer. Challenging future studies should focus on the structural characterization of intact co-regulator multiprotein complexes with RXR-RAR to decipher the interconnected links between ligand, DNA, PTMs and co-regulator complexes. Beyond structural aspects, the complex mechanistic underpinning of the RXR-RAR heterodimer action needs further exploration. Notably, in addition to the canonical nuclear function of RARs to regulate transcription through the RXR-RAR heterodimer, nonconventional non-genomic effects of these proteins have been reported enlarging the spectrum of their biological activities. In response to ATRA, RARs integrate a variety of signaling pathways, notably through PTMs such as phosphorylation [10, 53-55]. In several cell types, a few percent of RAR proteins are present in the cytosol or in membrane lipid rafts in association with PI3K or Src kinases [56, 57]. ATRA binding to this membrane fraction of RARs rapidly provokes cascades of transient interaction and activation of various kinases, thereby propagating signals to cytosolic or nuclear machineries. These ATRA-activated kinases can phosphorylate nuclear proteins involved in the transcription of RXR-RAR target genes such as histones and co-regulators. Importantly, through both LBDs and AF-1 domains, RARs are substrates for various kinases activated by a variety of signals, but are also themselves phosphorylated by ATRA-activated kinases, affecting RAR binding to DNA, co-regulators recruitment, and degradation [58]. Accordingly, all these phosphorylation mechanisms likely cooperate to coordinate and adjust the dynamic exchanges between RARs, co-regulators and the promoters of target genes [59]. A current challenge is to decipher more precisely how RARs integrate membrane and cytoplasm events, and the crosstalk with the well-established genomic effects. 
Such a quest can be achieved through global genomic technologies based on next generation deep sequencing methodology [60]. These approaches now make it possible to integrate global binding of transcription factors, epigenetic chromatin histone and DNA modification patterns with transcriptomes and three-dimensional chromatin structures. In this way genome-wide high throughput sequencing and chromatin immunoprecipitation coupled with deep sequencing contributed insights into how RXRRAR heterodimers mediate transcriptional regulation [26, 27, 29-32, 61]. Noticeably several studies in various cell types have identified genome-wide RXR-RAR binding sites and gave us a more comprehensive RXR-RAR binding picture [31, 32]. Interestingly, the interaction of heterodimers with regions containing the DR0 motif is predominant in undifferentiated pluripotent embryonic cells [32], while in differentiated cells such as MCF-7, the RXR-RAR bound regions are characterized by a higher frequency of the canonical DR5 sequence [27], highlighting the reorganization of the RXRRAR binding repertoire during the differentiation process. Further studies on these newly identified RAREs should elucidate their relevance to RXR-RAR function and whether they may be associated with particular transcription factor binding patterns, epigenetic markings and chromatin structures.

Another intriguing fact we learned from the global genomic data analyses is that RAR binding is dynamically regulated by ligand treatment or cell differentiation status $[30,32]$. These data revealed the dynamic occupancy of chromatin by pre-existing and de novo recruited RXR-RAR heterodimers, as well as heterodimer replacement or even partner swaps [32]. The observed ATRA-dependent RAR subunit recruitment may therefore likely reflect the increased ability of RXR-phospho-RAR heterodimers to interact with their target DNA sequences [62]. Furthermore, although RXR-RAR heterodimers can bind constitutively to target sites, the massive increase in the number of RXR-RAR bound genomic loci after ATRA stimulation calls into question the classical model for the heterodimer action postulating that a major effect of ligand-dependent activation is to convert preexisting DNAbound heterodimers from an inhibitory to an activating complex (Fig. 1), as well the widely accepted mechanism of repression by unliganded RXR-RAR. The molecular determinants of such various mechanisms remain to be explored.

This last observation highlights that, while the above genome-wide experiments, although useful, determine average properties of the RXR-RAR signaling in the context of cell population at single 
time points, our understanding of RXR-RAR transcriptional action at the level of individual cells or individual target gene alleles remains broadly incomplete. The development of novel single-cell and single-molecule imaging technologies has repositioned biological questions on gene expression [63] and recent works dealing with other NRs have started addressing this issue [64, 65]. These experiments revealed the stochastic nature of transcription which occurs predominantly as burst, but the mechanisms regulating this process are unclear [66]. Together, with recent advances in CRISPRCas technology that have greatly facilitated genome editing and RNA labeling for live cell imaging [67], these imaging methods should be applied to RXR-RAR to explore the relationship between ligand binding, heterodimer dynamics, co-regulator association/ disassociation, and RNA bursting. This approach may isolate and question the behavior and influence of each of the regulators of the RXR-RAR signaling on the transcriptional output. Overall, future challenges are to connect data from new, highly sensitive technologies, in real time or on a large scale, to obtain critical new information on the influence of DNA- and ligand-binding, and phosphorylation processes on the regulation of RXR-RAR heterodimer activities.

\section{Author contributions}

All authors contributed to writing the manuscript and preparing the Figures.

\section{Acknowledgments}

We would like to acknowledge the financial support from the Agence Nationale de la Recherche (grant ANR-11-BSV8-023 to NR). The CBS and IGBMC are members of French Infrastructure for Integrated Structural Biology (FRISBI), a national infrastructures supported by the Agence Nationale de la Recherche (grant ANR-10-INBS-05). 


\section{References}

[1] Germain P, Chambon P, Eichele G, Evans RM, Lazar MA, Leid M, et al. International Union of Pharmacology. LX. Retinoic acid receptors. Pharmacol Rev. 2006 Dec;58(4):712-25.

[2] Gutierrez-Mazariegos J, Schubert M, Laudet V. Evolution of retinoic acid receptors and retinoic acid signaling. Sub-cellular biochemistry. 2014;70:55-73.

[3] Rochette-Egly C. Retinoic Acid-Regulated Target Genes During Development: Integrative Genomics Analysis. Sub-cellular biochemistry. 2020;95:57-85.

[4] Duong V, Rochette-Egly C. The molecular physiology of nuclear retinoic acid receptors. From health to disease. Biochimica et biophysica acta. 2011 Aug;1812(8):1023-31.

[5] Ghyselinck NB, Duester G. Retinoic acid signaling pathways. Development (Cambridge, England). 2019 Jul 4;146(13).

[6] di Masi A, Leboffe L, De Marinis E, Pagano F, Cicconi L, Rochette-Egly C, et al. Retinoic acid receptors: from molecular mechanisms to cancer therapy. Molecular aspects of medicine. 2015 Feb;41:1-115.

[7] Uray IP, Dmitrovsky E, Brown PH. Retinoids and rexinoids in cancer prevention: from laboratory to clinic. Seminars in oncology. $2016 \mathrm{Feb}$;3(1):49-64.

[8] le Maire A, Alvarez S, Shankaranarayanan P, Lera AR, Bourguet W, Gronemeyer H. Retinoid receptors and therapeutic applications of RAR/RXR modulators. Current topics in medicinal chemistry. 2012;12(6):505-27.

[9] Liu Z, Hu Q, Rosenfeld MG. Complexity of the RAR-mediated transcriptional regulatory programs. Sub-cellular biochemistry. 2014;70:203-25.

[10] Piskunov A, Al Tanoury Z, Rochette-Egly C. Nuclear and extra-nuclear effects of retinoid acid receptors: how they are interconnected. Sub-cellular biochemistry. 2014;70:103-27.

[11] Huang P, Chandra V, Rastinejad F. Structural overview of the nuclear receptor superfamily: insights into physiology and therapeutics. Annual review of physiology. 2014;72:247-72.

[12] Khorasanizadeh S, Rastinejad F. Visualizing the Architectures and Interactions of Nuclear Receptors. Endocrinology. 2016 Nov; 157(11):4212-21.

[13] Lonard DM, O'Malley B W. Nuclear receptor coregulators: judges, juries, and executioners of cellular regulation. Molecular cell. 2007 Sep 7;27(5):691-700.

[14] Perissi V, Jepsen K, Glass CK, Rosenfeld MG. Deconstructing repression: evolving models of co-repressor action. Nature reviews. $2010 \mathrm{Feb}$;11(2):109-23.

[15] Kato S, Fujiki R. Transcriptional controls by nuclear fat-soluble vitamin receptors through chromatin reorganization. Bioscience, biotechnology, and biochemistry. 2011;75(3):410-3.

[16] Dasgupta S, O'Malley BW. Transcriptional coregulators: emerging roles of SRC family of coactivators in disease pathology. Journal of molecular endocrinology. 2014 Oct;53(2):R47-59.

[17] Jin L, Martynowski D, Zheng S, Wada T, Xie W, Li Y. Structural basis for hydroxycholesterols as natural ligands of orphan nuclear receptor RORgamma. Molecular endocrinology (Baltimore, Md. 2010 May;24(5):923-9.

[18] Bourguet W, Germain P, Gronemeyer H. Nuclear receptor ligand-binding domains: threedimensional structures, molecular interactions and pharmacological implications. Trends Pharmacol Sci. 2000 Oct;21(10):381-8.

[19] le Maire A, Bourguet W. Retinoic acid receptors: structural basis for coregulator interaction and exchange. Sub-cellular biochemistry. 2014;70:37-54.

[20] le Maire A, Germain P, Bourguet W. Protein-protein interactions in the regulation of RARRXR heterodimers transcriptional activity. Methods in enzymology. 2020;637:175-207.

[21] Brelivet Y, Kammerer S, Rochel N, Poch O, Moras D. Signature of the oligomeric behaviour of nuclear receptors at the sequence and structural level. EMBO reports. 2004 Apr;5(4):423-9.

[22] Rochel N, Moras D. Architecture of DNA Bound RAR heterodimers. Sub-cellular biochemistry. 2014;70:21-36.

[23] Brelivet Y, Rochel N, Moras D. Structural analysis of nuclear receptors: from isolated domains to integral proteins. Molecular and cellular endocrinology. 2012 Jan 30;348(2):466-73.

[24] Guillien M, le Maire A, Mouhand A, Bernado P, Bourguet W, Baneres JL, et al. IDPs and their complexes in GPCR and nuclear receptor signaling. Progress in molecular biology and translational science. 2020;174:105-55. 
[25] Mangelsdorf DJ, Evans RM. The RXR heterodimers and orphan receptors. Cell. 1995 Dec $15 ; 83(6): 841-50$.

[26] Delacroix L, Moutier E, Altobelli G, Legras S, Poch O, Choukrallah MA, et al. Cell-specific interaction of retinoic acid receptors with target genes in mouse embryonic fibroblasts and embryonic stem cells. Molecular and cellular biology. 2010 Jan;30(1):231-44.

[27] Ross-Innes CS, Stark R, Holmes KA, Schmidt D, Spyrou C, Russell R, et al. Cooperative interaction between retinoic acid receptor-alpha and estrogen receptor in breast cancer. Genes \& development. 2010 Jan 15;24(2):171-82.

[28] Martens JH, Brinkman AB, Simmer F, Francoijs KJ, Nebbioso A, Ferrara F, et al. PMLRARalpha/RXR Alters the Epigenetic Landscape in Acute Promyelocytic Leukemia. Cancer cell. 2010 Feb 17;17(2):173-85.

[29] Mahony S, Mazzoni EO, McCuine S, Young RA, Wichterle H, Gifford DK. Ligand-dependent dynamics of retinoic acid receptor binding during early neurogenesis. Genome biology. 2011;12(1):R2.

[30] Mendoza-Parra MA, Walia M, Sankar M, Gronemeyer H. Dissecting the retinoid-induced differentiation of F9 embryonal stem cells by integrative genomics. Molecular systems biology. 2011 Oct 11;7:538.

[31] Moutier E, Ye T, Choukrallah MA, Urban S, Osz J, Chatagnon A, et al. Retinoic acid receptors recognize the mouse genome through binding elements with diverse spacing and topology. The Journal of biological chemistry. 2012 Jul 27;287(31):26328-41.

[32] Chatagnon A, Veber P, Morin V, Bedo J, Triqueneaux G, Semon M, et al. RAR/RXR binding dynamics distinguish pluripotency from differentiation associated cis-regulatory elements. Nucleic acids research. 2015 May 26;43(10):4833-54.

[33] Penvose A, Keenan JL, Bray D, Ramlall V, Siggers T. Comprehensive study of nuclear receptor DNA binding provides a revised framework for understanding receptor specificity. Nature communications. 2019 Jun 7;10(1):2514.

[34] Osz J, McEwen AG, Bourguet M, Przybilla F, Peluso-Iltis C, Poussin-Courmontagne P, et al. Structural basis for DNA recognition and allosteric control of the retinoic acid receptors RAR-RXR. Nucleic acids research. 2020 Sep 25;48(17):9969-85.

[35] Rastinejad F, Wagner T, Zhao Q, Khorasanizadeh S. Structure of the RXR-RAR DNAbinding complex on the retinoic acid response element DR1. The EMBO journal. 2000 Mar $1 ; 19(5): 1045-54$.

[36] Chandra V, Wu D, Li S, Potluri N, Kim Y, Rastinejad F. The quaternary architecture of RARbeta-RXRalpha heterodimer facilitates domain-domain signal transmission. Nature communications. 2017 Oct 11;8(1):868.

[37] Meijsing SH, Pufall MA, So AY, Bates DL, Chen L, Yamamoto KR. DNA binding site sequence directs glucocorticoid receptor structure and activity. Science (New York, NY. 2009 Apr 17;324(5925):407-10.

[38] Osz J, McEwen AG, Wolf J, Poussin-Courmontagne P, Peluso-Iltis C, Chebaro Y, et al. Modulation of RXR-DNA complex assembly by DNA context. Molecular and cellular endocrinology. 2019 Feb 5;481:44-52.

[39] le Maire A, Teyssier C, Erb C, Grimaldi M, Alvarez S, de Lera AR, et al. A unique secondarystructure switch controls constitutive gene repression by retinoic acid receptor. Nat Struct Mol Biol. $2010 \mathrm{Jul} ; 17(7): 801-7$.

[40] Nadendla E, Teyssier C, Delfosse V, Vivat V, Krishnasamy G, Gronemeyer H, et al. An Unexpected Mode Of Binding Defines BMS948 as A Full Retinoic Acid Receptor beta (RARbeta, NR1B2) Selective Agonist. PloS one. 2015;10(5):e0123195.

[41] Senicourt L, le Maire A, Allemand F, Carvalho JE, Guee L, Germain P, et al. Structural Insights into the Interaction of the Intrinsically Disordered Co-activator TIF2 with Retinoic Acid Receptor Heterodimer (RXR/RAR). Journal of molecular biology. 2021 Apr 30;433(9):166899.

[42] Nahoum V, Perez E, Germain P, Rodriguez-Barrios F, Manzo F, Kammerer S, et al. Modulators of the structural dynamics of the retinoid X receptor to reveal receptor function. Proc Natl Acad Sci U S A. 2007 Oct 30;104(44):17323-8.

[43] le Maire A, Teyssier C, Balaguer P, Bourguet W, Germain P. Regulation of RXR-RAR Heterodimers by RXR- and RAR-Specific Ligands and Their Combinations. Cells. 2019 Nov 5;8(11). 
[44] Bourguet W, Vivat V, Wurtz JM, Chambon P, Gronemeyer H, Moras D. Crystal structure of a heterodimeric complex of RAR and RXR ligand-binding domains. Molecular cell. 2000 Feb;5(2):28998.

[45] Rochel N, Ciesielski F, Godet J, Moman E, Roessle M, Peluso-Iltis C, et al. Common architecture of nuclear receptor heterodimers on DNA direct repeat elements with different spacings. Nat Struct Mol Biol. 2011 May;18(5):564-70.

[46] de Vera IMS, Zheng J, Novick S, Shang J, Hughes TS, Brust R, et al. Synergistic Regulation of Coregulator/Nuclear Receptor Interaction by Ligand and DNA. Structure. 2017 Oct 3;25(10):150618 e4.

[47] Zheng J, Chang MR, Stites RE, Wang Y, Bruning JB, Pascal BD, et al. HDX reveals the conformational dynamics of DNA sequence specific VDR co-activator interactions. Nature communications. 2017 Oct 13;8(1):923.

[48] Pogenberg V, Guichou JF, Vivat-Hannah V, Kammerer S, Perez E, Germain P, et al. Characterization of the interaction between retinoic acid receptor/retinoid $X$ receptor (RAR/RXR) heterodimers and transcriptional coactivators through structural and fluorescence anisotropy studies. The Journal of biological chemistry. 2005 Jan 14;280(2):1625-33.

[49] Cordeiro TN, Sibille N, Germain P, Barthe P, Boulahtouf A, Allemand F, et al. Interplay of Protein Disorder in Retinoic Acid Receptor Heterodimer and Its Corepressor Regulates Gene Expression. Structure. 2019 Aug 6;27(8):1270-85 e6.

[50] $\mathrm{Hu}$ X, Li Y, Lazar MA. Determinants of CoRNR-dependent repression complex assembly on nuclear hormone receptors. Molecular and cellular biology. 2001;21(5):1747-58.

[51] Germain P, Iyer J, Zechel C, Gronemeyer H. Coregulator recruitment and the mechanism of retinoic acid receptor synergy. Nature. 2002;415:187-92.

[52] Germain P, Gaudon C, Pogenberg V, Sanglier S, Van Dorsselaer A, Royer CA, et al. Differential action on coregulator interaction defines inverse retinoid agonists and neutral antagonists. Chem Biol. 2009 May 29;16(5):479-89.

[53] Rochette-Egly C, Germain P. Dynamic and combinatorial control of gene expression by nuclear retinoic acid receptors (RARs). Nuclear receptor signaling. 2009 May 8;7:e005.

[54] Xu A, Zhang N, Cao J, Zhu H, Yang B, He Q, et al. Post-translational modification of retinoic acid receptor alpha and its roles in tumor cell differentiation. Biochemical pharmacology. 2020 Jan; 171:113696.

[55] Bruck N, Vitoux D, Ferry C, Duong V, Bauer A, de The H, et al. A coordinated phosphorylation cascade initiated by p38MAPK/MSK1 directs RARalpha to target promoters. The EMBO journal. 2009 Jan 7;28(1):34-47.

[56] Dey N, De PK, Wang M, Zhang H, Dobrota EA, Robertson KA, et al. CSK controls retinoic acid receptor (RAR) signaling: a RAR-c-SRC signaling axis is required for neuritogenic differentiation. Molecular and cellular biology. 2007 Jun;27(11):4179-97.

[57] Masia S, Alvarez S, de Lera AR, Barettino D. Rapid, nongenomic actions of retinoic acid on phosphatidylinositol-3-kinase signaling pathway mediated by the retinoic acid receptor. Molecular endocrinology (Baltimore, Md. 2007 Oct;21(10):2391-402.

[58] Bastien J, Rochette-Egly C. Nuclear retinoid receptors and the transcription of retinoid-target genes. Gene. 2004 Mar 17;328:1-16.

[59] Chebaro Y, Sirigu S, Amal I, Lutzing R, Stote RH, Rochette-Egly C, et al. Allosteric Regulation in the Ligand Binding Domain of Retinoic Acid Receptorgamma. PloS one. 2017;12(1):e0171043.

[60] Carrier M, Joint M, Lutzing R, Page A, Rochette-Egly C. Phosphoproteome and Transcriptome of RA-Responsive and RA-Resistant Breast Cancer Cell Lines. PloS one. 2016;11(6):e0157290.

[61] Hua S, Kittler R, White KP. Genomic antagonism between retinoic acid and estrogen signaling in breast cancer. Cell. 2009 Jun 26;137(7):1259-71.

[62] Al Tanoury Z, Gaouar S, Piskunov A, Ye T, Urban S, Jost B, et al. Phosphorylation of the retinoic acid receptor RARgamma2 is crucial for the neuronal differentiation of mouse embryonic stem cells. Journal of cell science. 2014 May 1;127(Pt 9):2095-105.

[63] Vera M, Biswas J, Senecal A, Singer RH, Park HY. Single-Cell and Single-Molecule Analysis of Gene Expression Regulation. Annual review of genetics. 2016 Nov 23;50:267-91. 
[64] Stavreva DA, Garcia DA, Fettweis G, Gudla PR, Zaki GF, Soni V, et al. Transcriptional Bursting and Co-bursting Regulation by Steroid Hormone Release Pattern and Transcription Factor Mobility. Molecular cell. 2019 Sep 19;75(6):1161-77 e11.

[65] Stossi F, Dandekar RD, Mancini MG, Gu G, Fuqua SAW, Nardone A, et al. Estrogen-induced transcription at individual alleles is independent of receptor level and active conformation but can be modulated by coactivators activity. Nucleic acids research. 2020 Feb 28;48(4):1800-10.

[66] Lionnet T, Singer RH. Transcription goes digital. EMBO reports. 2012 Apr 2;13(4):313-21.

[67] Rodriguez J, Ren G, Day CR, Zhao K, Chow CC, Larson DR. Intrinsic Dynamics of a Human Gene Reveal the Basis of Expression Heterogeneity. Cell. 2019 Jan 10;176(1-2):213-26 e18. 
Table 1. Chemical structures of the retinoids cited in this review.

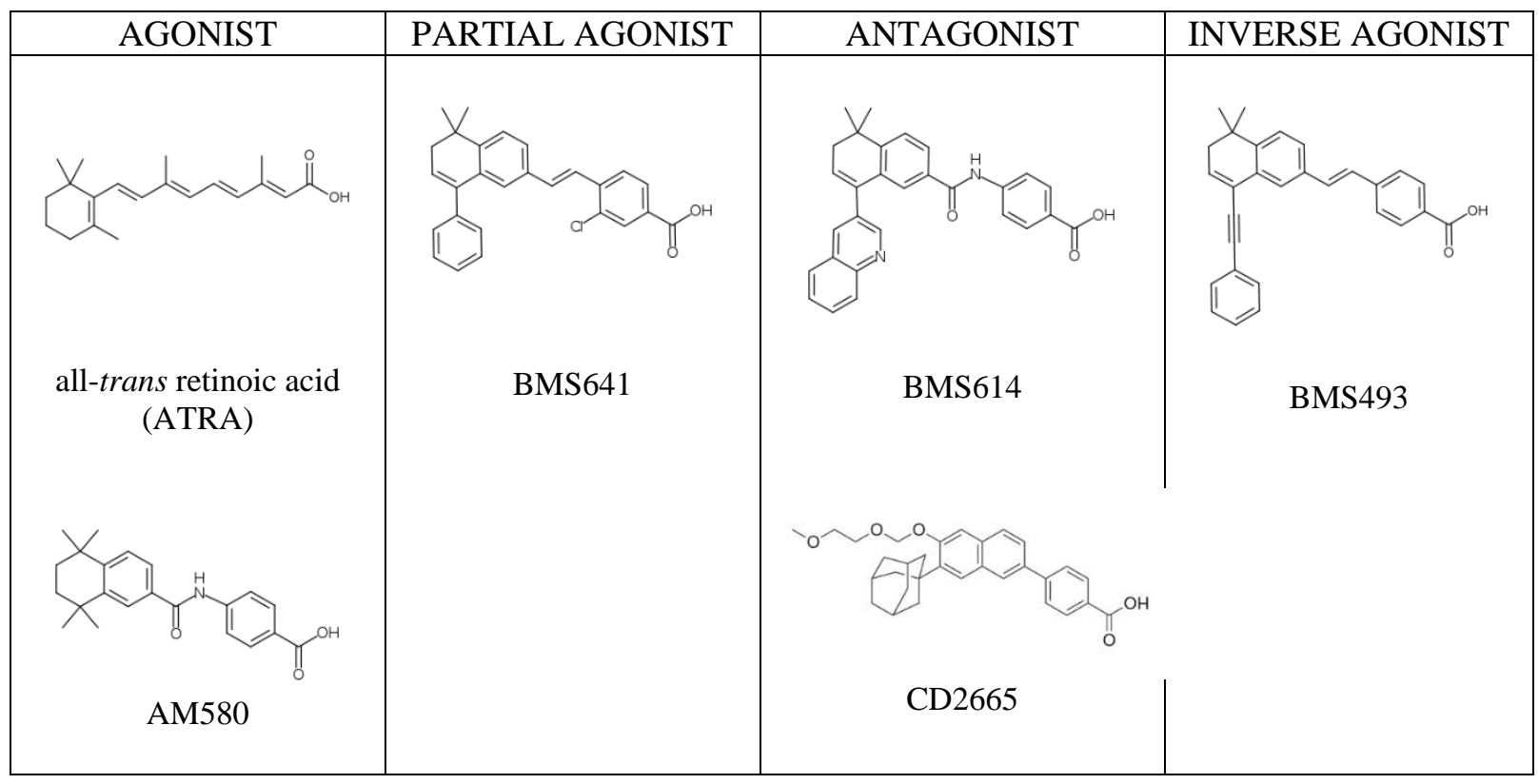

